\title{
Regional investigation of a cyclosporiasis outbreak linked to imported romaine lettuce - Nebraska and Iowa, June-August 2013
}

\author{
B. F. BUSS ${ }^{1,2 * \dagger}$, M. V. JOSHI ${ }^{1,3} \dagger$, A. L. O'KEEFE ${ }^{4}$, C. D. ALLENSWORTH ${ }^{4}$, \\ A. GARVEY ${ }^{5}, \mathrm{~K}$. OBBINK ${ }^{5}$, S. MANDERNACH ${ }^{6}$ AND T. J. SAFRANEK ${ }^{1}$ \\ ${ }^{1}$ Division of Public Health, Nebraska Department of Health and Human Services, Lincoln, NE, USA \\ ${ }^{2}$ Office of Public Health Preparedness and Response, Centers for Disease Control and Prevention, Atlanta, GA, \\ USA \\ ${ }^{3}$ University of Nebraska-Lincoln, Lincoln, NE, USA \\ ${ }^{4}$ Douglas County Health Department, Omaha, NE, USA \\ ${ }^{5}$ Division of Acute Disease Prevention, Emergency Response, and Environmental Health, Iowa Department of \\ Public Health, Des Moines, IA, USA \\ ${ }^{6}$ Iowa Department of Inspections and Appeals, Des Moines, IA, USA
}

Received 12 June 2015; Final revision 21 September 2015; Accepted 21 September 2015; first published online 22 October 2015

\section{SUMMARY}

A regional, multistate investigation into a June-August 2013 cyclosporiasis outbreak was conducted in Nebraska, Iowa, and neighbouring states. Cases were confirmed on the basis of laboratory and clinical findings. Of 227 cases in Iowa $(n=140)$ and Nebraska $(n=87)$ residents, $162(71 \%)$ reported dining at chain A/B restaurants $-96 \%$ reported house salad consumption. A case-control study identified chain A/B house salad as the most likely vehicle. Traceback was conducted to ascertain production lot codes of bagged salad mix (iceberg and romaine lettuce, red cabbage, and carrots) served as house salad in implicated restaurants. A single production lot code of salad mix supplied by both a common producer and distributor was linked to the majority of confirmed cases in persons reporting regional chain $\mathrm{A} / \mathrm{B}$ exposure. The salad mix linked to illnesses contained imported romaine lettuce from two separate single-grower fields-of-origin and $\geqslant 1$ additional field from another grower.

Key words: Cyclospora, epidemiology, foodborne infections, outbreaks, parasites.

\section{INTRODUCTION}

During 2013, US state and local public health officials, the Centers for Disease Control and Prevention (CDC), and the US Food and Drug Administration (FDA) investigated increased incidence of cyclosporiasis

\footnotetext{
* Author for correspondence: B. F. Buss, DVM, MPH, DACVPM, CDC Career Epidemiology Field Officer (CEFO), Nebraska Department of Health and Human Services, 301 Centennial Mall South, PO Box 95026, Lincoln, NE 68509, USA.

(Email: bryan.buss@nebraska.gov)

$\dagger$ These authors contributed equally as joint first authors.
}

$[1,2]$. Of 631 US cases reported during June-August 2013, at least 25 were linked to Mexico-origin cilantro only in Texas [3]. In Iowa and Nebraska, respectively, 140 and 87 cases occurred. Investigations in these US Upper Midwest states linked illnesses to producer A, Mexico-origin salad mix containing iceberg and romaine lettuce, red cabbage, and carrots [2]. This product was served in two distinctly different restaurant chains (A/ B) that shared both a common supply channel and parent corporation, company D [4]. We report the methods and findings that implicated the chain $\mathrm{A} / \mathrm{B}$ salad mix and additional investigative activities that further 
establish the specific salad-mix ingredient as the cause of many cyclosporiasis cases in the US Upper Midwest.

Cyclosporiasis is an intestinal infection caused by the unicellular, coccidian parasite Cyclospora cayetanensis [5]. Humans are the only known host of this species transmitted by ingestion of infective oocysts, generally through contaminated food or water. Incubation typically ranges from 2 to 14 days, but can be longer. Watery diarrhoea is the most common symptom [6, 7]. Cyclosporiasis generally responds well to treatment, but prolonged illness lasting several weeks to months is common in untreated persons [5, 6]. Oocysts shed in faeces of infected persons require days to weeks of favourable environmental conditions to sporulate and become infective [5]. Direct person-to-person spread is an unlikely mode of transmission [6,7]. Although Cyclospora is not considered endemic in the United States, outbreaks since the mid-1990s have been linked to fresh, imported produce including raspberries, basil, snow peas, and mesclun lettuce [5].

Beyond the initial outbreak reports $[1,2,4,8,9]$, limited additional information was published to link illnesses to the chain $\mathrm{A} / \mathrm{B}$ salad mix, or to establish the origin of its contamination. We conducted a regional, multistate investigation into cases in Nebraska, Iowa, Missouri, Kansas, Wisconsin, and Illinois with the objectives of identifying production lot codes (PCs) of implicated products, specific salad-mix ingredient(s) associated with illness, and the growing fields where product contamination might have occurred. These findings helped guide environmental assessment activities [8] and can inform prevention recommendations.

\section{METHODS}

\section{Case ascertainment}

All laboratory-confirmed cyclosporiasis cases identified from 1 June to 31 August 2013 in Nebraska, Iowa, Missouri, Kansas, Wisconsin, and Illinois were investigated. Structured questionnaires were administered to study food exposures within 14 days of illness onset. A confirmed case was defined as laboratory-confirmed Cyclospora infection in a person with symptom onset from 1 June to 31 August 2013 with no history of travel outside the United States or Canada 14 days prior to illness onset. After initial interviews suggested an association with chain $\mathrm{A} / \mathrm{B}$, a refined questionnaire was administered focusing on fresh produce and chain A/B restaurant salad exposures, including lettuce type.

\section{Douglas County environmental investigation and case-control study}

An environmental investigation was conducted in Douglas County (Nebraska) to identify chain A and chain B menu item ingredients, including salad types and garnishes. Using restaurant menus, food exposure and illness histories were obtained using a standardized questionnaire for confirmed ill persons and their dining partners. A case-control study assessed the food exposures of ill patrons and dining partners who reported eating at chain $\mathrm{A} / \mathrm{B}$ restaurants in this county. A probable case was defined as clinically compatible illness in a person reporting onset $\leqslant 2$ weeks after sharing a chain A/B meal with a confirmed ill person. Non-ill dining partners served as unmatched controls. Exposures assessed included the most commonly reported main entrées and other items which shared common supply channels. Data were analysed using Epi-Info v. 7 (CDC, USA) and SAS (SAS Institute Inc., USA).

\section{Regional product traceback}

Traceback information collected included names of growers, producers, distributors, and the lot codes of various shipments. All data collected were anonymized to protect commercial confidentiality. Company D named and provided the locations for its chain A/ B restaurants in Nebraska, Iowa, Kansas, Missouri, Wisconsin, South Dakota, and Illinois. A product traceback investigation was initiated to identify PCs of chain A/B salad-mix product likely causing restaurant-associated illness and to ascertain product origin. Figure 1 gives an overview of distribution channels from producer A's Mexican processing facility to final points-of-service.

Chain A/B house salad exposure compared to product distribution and service dates

We mapped exposures of ill persons and superimposed these on the entire distributor $X$ chain $A / B$ supply chain. We also constructed an epidemic curve to plot dates when PC-specific salad-mix products were delivered and thus available for possible service at each chain A/B restaurant (assuming 14-day shelf life) for comparison to corresponding dining dates of ill persons. For the latter, we restricted analysis to only confirmed ill persons reporting specific restaurant location, house salad consumption, and known dining date. 


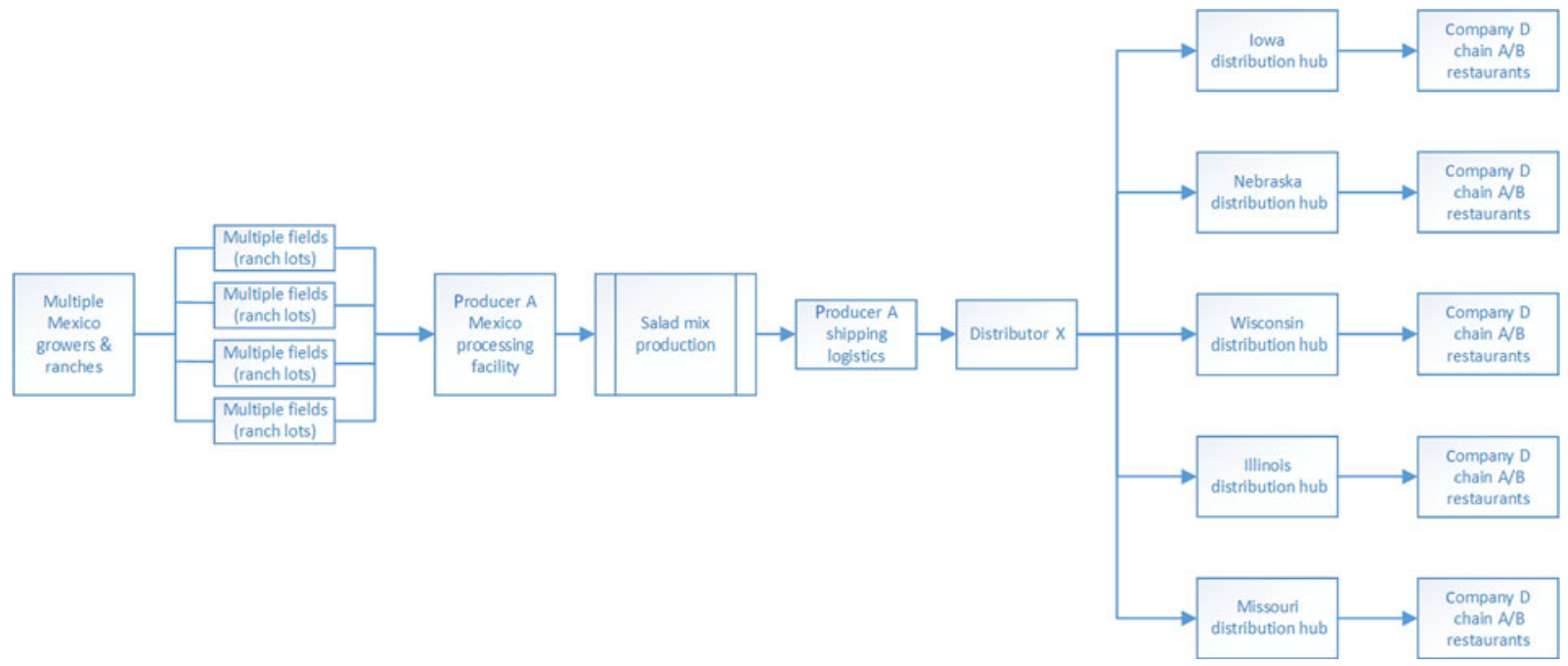

Fig. 1. General overview of the possible distribution channels* by which potentially contaminated producer A salad mix was supplied from Mexico-origin growers and fields (growing lots) through distributor $\mathrm{X} \dagger$ to chain $\mathrm{A} / \mathrm{B}$ restaurants in Iowa, Nebraska, and surrounding states, May-June 2013. (* This flowchart is provided only as an overview of the distribution channels described in the text and associated tables. Accordingly, the channels depicted are not intended to demonstrate product movement to any specific final end point-of-service. $†$ Distributor $\mathrm{X}$ did not have a single physical location. Product was delivered directly to the various distribution hubs by producer A.)

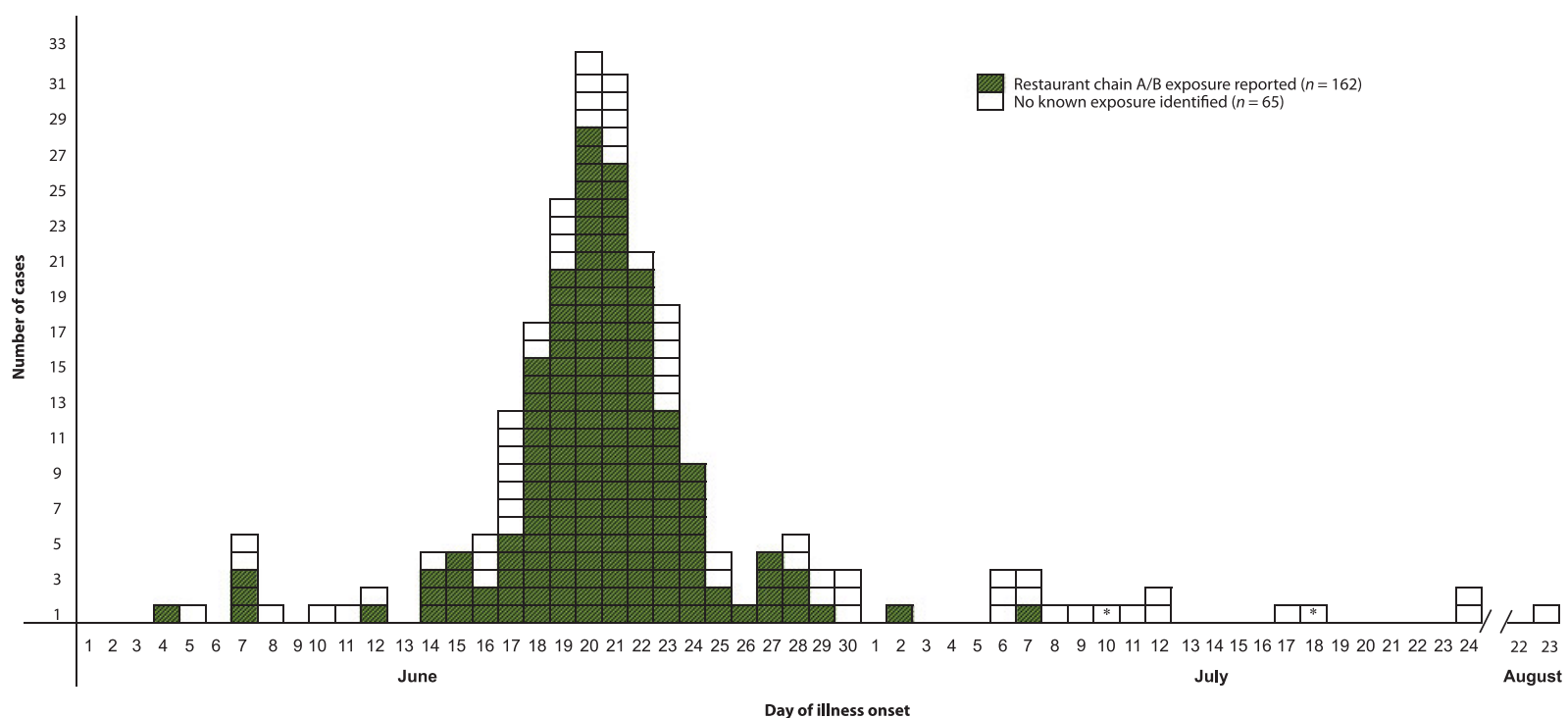

Fig. 2. Number of cyclosporiasis cases meeting case definition $(N=227)$ by date of onset and reported exposure, Iowa and Nebraska, June-August 2013. * Calculated onset date estimate using 12 days prior to specimen collection (observed mean for all cases).

A chain $A / B$ exposure was defined as consumption of $\geqslant 1$ chain $\mathrm{A} / \mathrm{B}$ meal $2-14$ days prior to illness onset.

\section{Determination of product origin for salad-mix ingredients}

Initial source product records supplied by producer A in early August 2013 included grower, production, and distribution information for limited numbers of products and subcomponents of mixed products. These records implicated the salad mix but were inadequate to determine a specific ingredient that was probably contaminated. Further, these data contained erroneous grower information yet inaccuracies were not apparent at that time. At the request of FDA, producer A later provided more comprehensive records in November 2013. This information contained corrected field-level (ranch lot level) grower-specific data for 
Table 1. Chain A/B restaurant food exposures reported by patrons $(N=77)$ in a cyclosporiasis investigation and corresponding odds ratios, Douglas County, Nebraska, June-July 2013

\begin{tabular}{|c|c|c|c|c|c|c|c|c|c|}
\hline \multirow[b]{3}{*}{ Food } & \multicolumn{4}{|c|}{ Cases $(N=40)$} & \multicolumn{4}{|c|}{ Controls $(N=37)$} & \multirow[b]{3}{*}{ OR $(95 \% \mathrm{CI})$} \\
\hline & \multicolumn{2}{|c|}{ Exposed } & \multicolumn{2}{|c|}{ Not exposed } & \multicolumn{2}{|c|}{ Exposed } & \multicolumn{2}{|c|}{ Not exposed } & \\
\hline & $n$ & $(\%)$ & $n$ & $(\%)$ & $n$ & $(\%)$ & $n$ & $(\%)$ & \\
\hline House salad* & 38 & (95) & 2 & (5) & 19 & $(51)$ & 18 & (49) & $18 \cdot 0(3 \cdot 8-85 \cdot 8)$ \\
\hline Basiltt & 5 & (13) & 31 & (78) & 2 & (5) & 30 & (81) & $2 \cdot 4(0.4-13 \cdot 4)$ \\
\hline Bread (breadsticks, bruschetta) & 12 & (30) & 28 & (70) & 9 & (24) & 28 & (76) & $1 \cdot 3(0 \cdot 5-3 \cdot 7)$ \\
\hline Pasta & 8 & (20) & 32 & (80) & 11 & $(30)$ & 26 & (70) & $0 \cdot 6(0 \cdot 2-1 \cdot 7)$ \\
\hline Shrimp & 13 & (33) & 27 & (68) & 6 & (16) & 31 & (84) & $2 \cdot 5(0 \cdot 8-7 \cdot 4)$ \\
\hline Chicken & 9 & (23) & 31 & (78) & 8 & (22) & 29 & (78) & $1 \cdot 1(0 \cdot 4-3 \cdot 1)$ \\
\hline Berry & 3 & (8) & 37 & (93) & 0 & $(0)$ & 37 & (100) & Undefined \\
\hline Any seafood & 14 & (35) & 26 & (65) & 7 & (19) & 30 & (81) & $2 \cdot 3(0 \cdot 8-6 \cdot 6)$ \\
\hline Caesar salad & 0 & $(0)$ & 40 & (100) & 1 & (3) & 36 & (97) & 0 \\
\hline
\end{tabular}

OR, Odds ratio; $\mathrm{CI}$, confidence interval.

* House salad contained producer A salad mix.

$\dagger$ Information on basil as an ingredient in all menu items from chains A and B was obtained from the corporate chef.

* Basil analysis excluded nine individuals (four ill, five not ill) for whom basil consumption was unknown.

products shipped from its Mexican production facility 15 May-1 July 2013 including corrected grower information for the salad-mix ingredients of the implicated PC.

After specific PCs and deliveries were linked to illnesses, we then used these corrected producer A data to assess field-level grower information to determine which ingredients in implicated PCs were likely contaminated. We compared the source ranch lots of ingredients in shipments to the distributor $\mathrm{X}$ hubs which were linked to illnesses with shipments to hub(s) not linked to illnesses.

\section{Ethical approval}

The investigative activity reported herein underwent CDC human participants review and was determined to be public health practice and not research; as such, Institutional Review Board approval was not required.

\section{RESULTS}

\section{Case ascertainment}

A total of 227 confirmed cyclosporiasis cases were identified in Iowa $(n=140)$ and Nebraska $(n=87)$; reported illness onset dates ranged from 4 June to 23 August 2013. Median age was 56 years (range 2-92), 136 $(60 \%)$ were female, $15(7 \%)$ were hospitalized, and no deaths were reported. Of the 227 ill Iowa and Nebraska residents, $162(71 \%)$ reported chain A/B restaurant exposure (100 chain A, 50 chain $\mathrm{B}$, and 12 both); 155 (96\%) reported salad consumption (Fig. 2). Of confirmed ill Wisconsin, Missouri, and Kansas residents, $22 \%$ (4/18), 20\% (1/5), and 50\% (2/4) reported chain $\mathrm{A} / \mathrm{B}$ exposure with salad consumption, respectively. In total, 169 persons reported chain A/B exposure of whom $162(96 \%)$ reported salad consumption.

\section{Douglas County environmental investigation and case-control study}

Both chain A and chain B restaurants used only producer A-supplied salad-mix product for house salads and both used bottled, processed dressings; no basil, cilantro, or other lettuce products were added. Both chains added garnishes to house salads; items in common included onions, tomatoes, and cucumbers. However, review of invoices demonstrated differing sources for these products in each chain. Both chains used producer $A$ chopped romaine for Caesar salad only and chain B used producer A shredded romaine only for entrée garnishes and sandwiches.

Forty case-patients (confirmed, $n=27$; probable, $n$ $=13$ ) with illness onsets ranging from 15 June to 2 July and 37 controls were identified for inclusion in a convenience sample analysis (Table 1). Dates of exposure ranged from 6 to 25 June 2013. Ninety-five percent $(38 / 40)$ of case-patients reported consuming chain A/B house salad compared to only $51 \%(19 /$ 37) of controls [Table 1; odds ratio (OR) 18.0, 95\% 


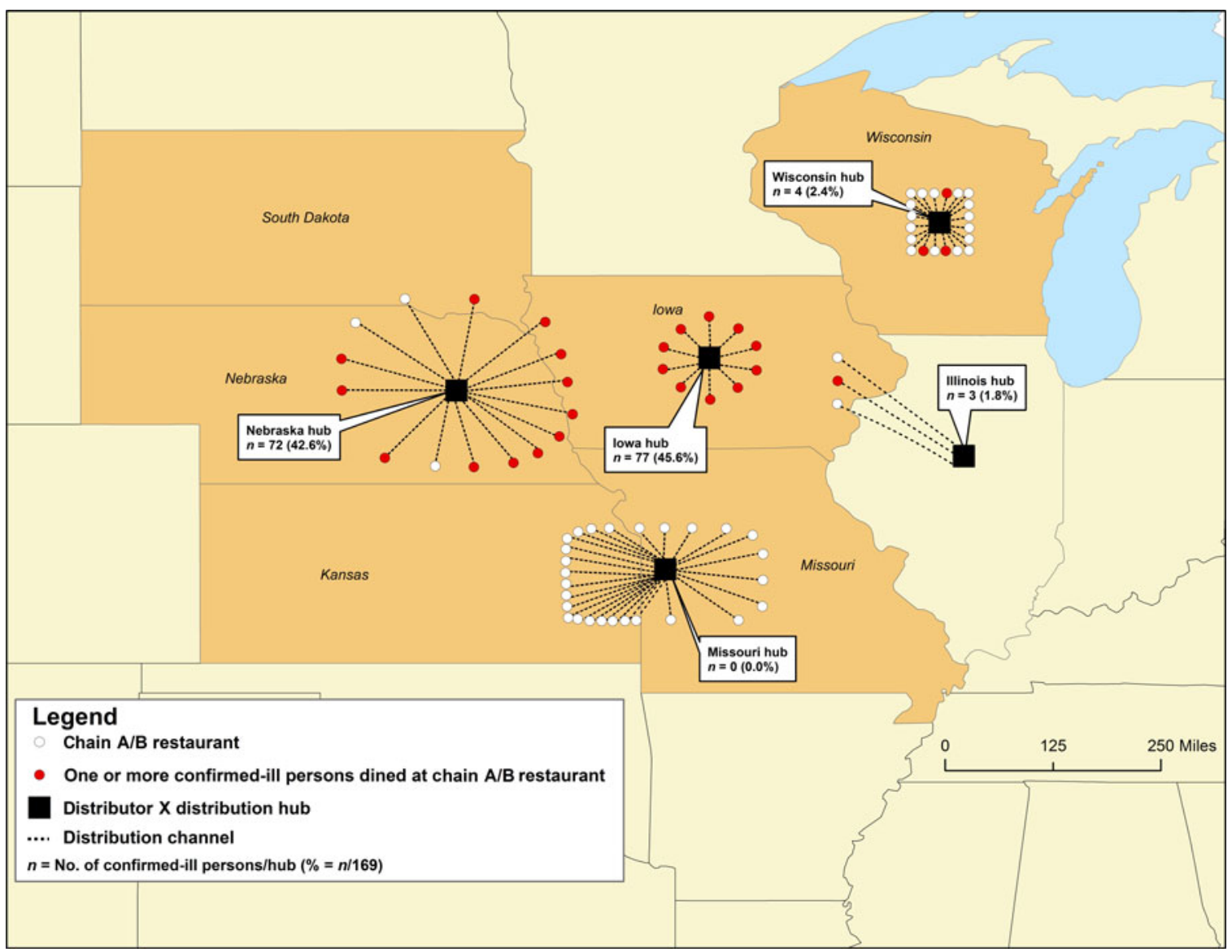

Fig. 3. Distribution channels for producer A salad mix supplied by distributor $\mathrm{X}$ distribution hubs to chain A/B restaurants: ${ }^{\dagger} \dagger$ including those $(n=26)$ reported by persons confirmed with cyclosporiasis $(N=169 \$)$, June-August 2013. (* Three distribution channels as provided by distributor $\mathrm{X}$ not depicted: from the Wisconsin distribution hub to a Michigan chain A/B restaurant where no illnesses were reported, and from both the Missouri and Illinois hubs to Wisconsin chain A/B restaurants (unable to verify the accuracy of the latter two; no illnesses were reported in these two restaurants). $\dagger$ Locations of all chain A/B restaurants and distribution hubs depicted herein are not intended to represent the specific geographical locations within the states in which they are located. No illnesses were reported in South Dakota but one chain A/B restaurant in the state was linked to a confirmed ill Iowa resident. \$ Thirteen (7.7\%) of 169 confirmed ill persons who reported chain A/B exposure but could not recall exact location of dining are not represented in this map.)

confidence interval (CI) 3.8-85.8]. No other menu item exposures had ORs which were statistically significant.

\section{Regional product traceback}

Producer A shipped product from its Mexican production facility directly to five distributor $\mathrm{X}$ distribution hubs located in Iowa, Nebraska, Wisconsin, Illinois, and Missouri (Fig. 1). Any given shipping day at least two trucks were used. Product packaging and shipping protocols suggested minimal risk of postpackaging product contamination. Distributor X provided detailed records (including item numbers, delivery dates, and PCs) on inbound imported producer A produce shipments and outbound salad mix and other deliveries to chain $\mathrm{A} / \mathrm{B}$ restaurants from all five regional distribution hubs during 1-10 June 2013 and only the Nebraska hub during 11-21 June.

\section{Chain AlB house salad exposure compared to product distribution and service dates}

The five distribution hubs are detailed in Figure 3 with corresponding chain $\mathrm{A} / \mathrm{B}$ restaurants in their respective service areas depicted by state of location. Within the entire distributor X service area, 169 confirmed ill persons reported chain A/B exposure (Table 2). Of these, $156(92 \%)$ reported exact location of dining; 144 were exposed in their home states and 12 in neighbouring states. The number of ill persons per restaurant varied 
Table 2. Number of persons with confirmed cyclosporiasis reporting restaurant chain $A / B$ exposure by state and illness onset date, Nebraska and Iowa region, 2013

\begin{tabular}{|c|c|c|c|c|}
\hline & \multicolumn{3}{|c|}{ Illness onset date, 2013} & \multirow[b]{2}{*}{ Total } \\
\hline & $\begin{array}{l}1-10 \\
\text { June }\end{array}$ & $\begin{array}{l}11 \text { June-1 } \\
\text { July }\end{array}$ & $\begin{array}{l}2 \text { July-14 } \\
\text { July }\end{array}$ & \\
\hline Iowa & 2 & 105 & 0 & 107 \\
\hline Nebraska & 2 & 51 & 2 & 55 \\
\hline Wisconsin & 0 & 3 & 1 & 4 \\
\hline Kansas & 0 & 2 & 0 & 2 \\
\hline Missouri & 0 & 1 & 0 & 1 \\
\hline Total & 4 & 162 & 3 & 169 \\
\hline
\end{tabular}

widely. Most exposures were reported at chain A/B restaurants supplied by the Iowa $(n=77)$ and Nebraska $(n=72)$ distributor $\mathrm{X}$ hubs (Table 3; range/restaurant $1-27$ cases). None of the 27 chain A/B restaurants within the Missouri hub's distribution area were ever reported by a confirmed ill person.

Figure 4 illustrates $\mathrm{PC}$-specific producer A shipping dates, distributor $\mathrm{X}$ chain $\mathrm{A} / \mathrm{B}$ delivery dates, corresponding date ranges of possible service given 14-day product shelf-life, and reported exposure dates for 120 confirmed ill persons who consumed house salad. Three Kansas $(n=2)$ and Missouri $(n=1)$ residents reported exposure in Nebraska. Distributor X did not track and could not name individual PCs included in any deliveries. Thus data to define specific PCs of salad-mix deliveries to each chain A/B restaurant were lacking. Likewise, neither company D nor the restaurants tracked $\mathrm{PC}$-specific information for product received and served. Figure 4 reflects this uncertainty listing 2-3 PCs potentially included in deliveries during a given time period. A company D representative did indicate that salad-mix product was invariably served and out of inventory before use-by dates; however, information to definitively establish precise timing of product turnover was lacking. Of 120 ill persons represented in Figure 4, 105 (88\%) reported dining within the possible service of PC-M or PC-T; both were delivered 7-12 June and potentially served up to 17 June.

\section{Determination of product origin for salad-mix ingredients}

The salad-mix product implicated in the Douglas County case-control study contained iceberg (75\%) and romaine $(15 \%)$ lettuce, carrots $(5 \%)$, and red cabbage $(5 \%)$. Table 4 lists distribution by PC of producer A salad-mix boxes shipped 27 May-10 June to the five distributor $\mathrm{X}$ hubs for subsequent 1-17 June delivery to chain $\mathrm{A} / \mathrm{B}$ restaurants. The selected time period represents dates of product shipments that potentially could have been in service during the restaurant exposures reported by ill persons depicted in Figures 3 and 4. Of the two aforementioned PCs ( $\mathrm{M}$ and $\mathrm{T}$ ), PC-M was only delivered to Nebraska whereas PC-T salad mix was shipped during 7-12 June to all four distribution hubs linked to illnesses. This product was available for consumption 7-17 June in 26 chain A/B restaurants where the 169 confirmed ill persons reported exposure; PC-T was not shipped to the Missouri hub, which had no associated cases of illness (Table 4).

The romaine lettuce used in PC-T salad mix had a single, common field-of-origin (grower R/ranch R/lot R). Salad mix with four PCs (M, T, U, V) contained romaine lettuce from this single field-of-origin and was distributed through four of five distributor $\mathrm{X}$ hubs (Table 4). The Missouri distribution hub never received salad mix containing romaine lettuce from this growing field either as PC-T or as any other PC (Table 4, Supplementary Tables S1 and S3). By contrast, source growing fields for PC-T salad-mix carrots and red cabbage contributed to a much wider range of PCs, many of which shipped to the distributor $\mathrm{X}$ Missouri hub that was never connected with a single ill person (Supplementary Table S2). Further, the only PC-T iceberg lettuce growing field that had contributed to salad mix that was shipped (as either PC-T or other PCs) to each of the four distribution hubs that were connected with ill persons was grower $\mathrm{P} /$ ranch $\mathrm{P} /$ lot 1 (Supplementary Tables S1 and S2). However, salad mix containing iceberg lettuce from this growing field was also shipped to the Missouri hub (PC-A6). Beyond distributor $\mathrm{X}$ supply channels, producer $\mathrm{A}$ also shipped large volumes of grower $\mathrm{P} /$ ranch $\mathrm{P} /$ lot 1 iceberg lettuce in chain $\mathrm{A} / \mathrm{B}$ salad mix and other blended salad products to five distributors located in Indiana, Maryland, and North and South Carolina [Supplementary Table S2 (notes)]; these states did not identify a single outbreak-associated case of cyclosporiasis during June-August 2013 [2].

Ill persons with chain $A / B$ house salad exposure outside the PC-T service window

Figure 4 also demonstrates chain A/B house salad exposures reported both before $(n=3)$ and after 
Table 3. Number of confirmed cyclosporiasis cases $(N=169)$ reported by distributor $X$ distribution hub state and hub-specific mean, median, and range per chain A/B restaurant, Nebraska and Iowa region, 2013

\begin{tabular}{|c|c|c|c|c|c|c|}
\hline \multirow[b]{2}{*}{ State of distribution hub } & \multicolumn{2}{|c|}{$\begin{array}{l}\text { Reported cases } \\
\text { per distribution } \\
\text { hub }\end{array}$} & \multirow{2}{*}{$\begin{array}{l}\text { Chain A/B restaurants } \\
\text { per distribution hub* } \\
n\end{array}$} & \multicolumn{3}{|c|}{$\begin{array}{l}\text { Reported cases per restaurant by } \\
\text { distribution hub }(n)\end{array}$} \\
\hline & $n$ & $(\%)$ & & Mean & Median & Range \\
\hline Iowa & 77 & $(45 \cdot 6)$ & 10 & $7 \cdot 70$ & 6 & $1-27$ \\
\hline Nebraska & 72 & $(42 \cdot 6)$ & 15 & $4 \cdot 80$ & 2 & $0-22$ \\
\hline Wisconsin & 4 & $(2 \cdot 4)$ & 20 & $0 \cdot 19$ & 0 & $0-2$ \\
\hline Illinois & 3 & $(1 \cdot 8)$ & $3 \dagger$ & $0 \cdot 75$ & 0 & $0-3$ \\
\hline Missouri & 0 & $(0 \cdot 0)$ & 27 & $0 \cdot 00$ & 0 & n.a. \\
\hline Not reported $\$$ & 13 & $(7 \cdot 7)$ & n.a. & n.a. & n.a. & n.a. \\
\hline
\end{tabular}

n.a., Not available.

* Three distribution channels as provided by distributor X not included: one from the Wisconsin hub to a Michigan chain A/B restaurant where no illnesses were reported, and one each from the Missouri and Illinois hubs to Wisconsin chain A/B restaurants (the latter two were seemingly inconsistent on the basis of geography and information was lacking to verify accuracy; no illnesses were reported in either of these two Wisconsin restaurants).

$\dagger$ All three chain A/B restaurants served by the Illinois hub were located in Iowa. This distribution hub did not deliver to any chain $\mathrm{A} / \mathrm{B}$ restaurants in Illinois.

Thirteen (7.7\%) of 169 confirmed ill persons who reported chain A/B exposure could not recall the exact location of dining.

$(n=12)$ the time period of possible service of PC-T. Three confirmed ill Iowans recalled exact dining dates and house salad consumption during 1-6 June 2013. Of these, two reported illness onset before 9 June (Fig. 2). On 27 May 2013, producer A shipped salad mix to the Iowa (PC-A1), Illinois (PC-A4), and Wisconsin (PC-A4) distributor $\mathrm{X}$ hubs (Table 4). The immediately aforementioned producer A salad-mix shipments of 27 May (supplied to chain A/B restaurants associated with illness) contained romaine lettuce that originated from grower R/ranch $\mathrm{R} /$ lot $\mathrm{Q}$, a grower $\mathrm{R} /$ ranch $\mathrm{R}$ field most likely proximal to the lot $\mathrm{R}$ growing field, the romaine supplier for PC-T - both fields had sequential identifying field numbers as reported by producer A. The Nebraska distributor X hub also received grower R/ ranch R/lot Q product as chopped romaine (Table 4, note); two additional Nebraska cases with illness onset before 9 June were identified with chain A/B exposure within this hub's service area (Fig. 2).

After PC-T salad mix would have been completely out of inventories, ten ill Iowans dined in five restaurants during a 5-day period, 18-22 June (Fig. 4). Of these, one reported (18 June) dining at an Iowa chain A/B restaurant supplied by the Nebraska hub on both 14 and 17 June with salad mix containing grower Y/ranch Z/lot S romaine (Fig. 4, note). Distribution information was not available for the Iowa or Illinois distributor $\mathrm{X}$ hubs to definitively link other restaurants to illnesses. Notwithstanding, the remaining nine Iowans had patronized locations served by these hubs which also received salad mix containing romaine from grower $\mathrm{Y} /$ ranch $\mathrm{Z} /$ lot $\mathrm{S}$ (Table 4, Supplementary Tables S1 and S3).

\section{DISCUSSION}

Of 227 laboratory-confirmed cyclosporiasis cases in Iowa and Nebraska residents, $162(71 \%)$ reported dining at 23 chain A/B restaurants, $96 \%$ reported salad consumption consistent with exposure to producer A-supplied romaine lettuce. Our regional investigation identified seven additional cyclosporiasis cases in patrons of three Wisconsin chain A/B restaurants and in Missouri and Kansas residents reporting exposure in Nebraska. Product distribution records traced back to individual growing fields combined with chain A/B restaurant house salad consumption and known exposure dates linked illnesses to a single production lot code of romaine lettuce (PC-T). This romaine from a common-origin growing field (grower R/ranch R/lot R) was the likely cause of cyclosporiasis for chain A/B restaurant patrons with 11 June-1 July 2013 illness onset.

Additional cases in chain A/B patrons with illness onset both before and after the main cluster appear related to producer A products that contained romaine lettuce from at least two other growing fields although corroborating evidence presented herein is less 


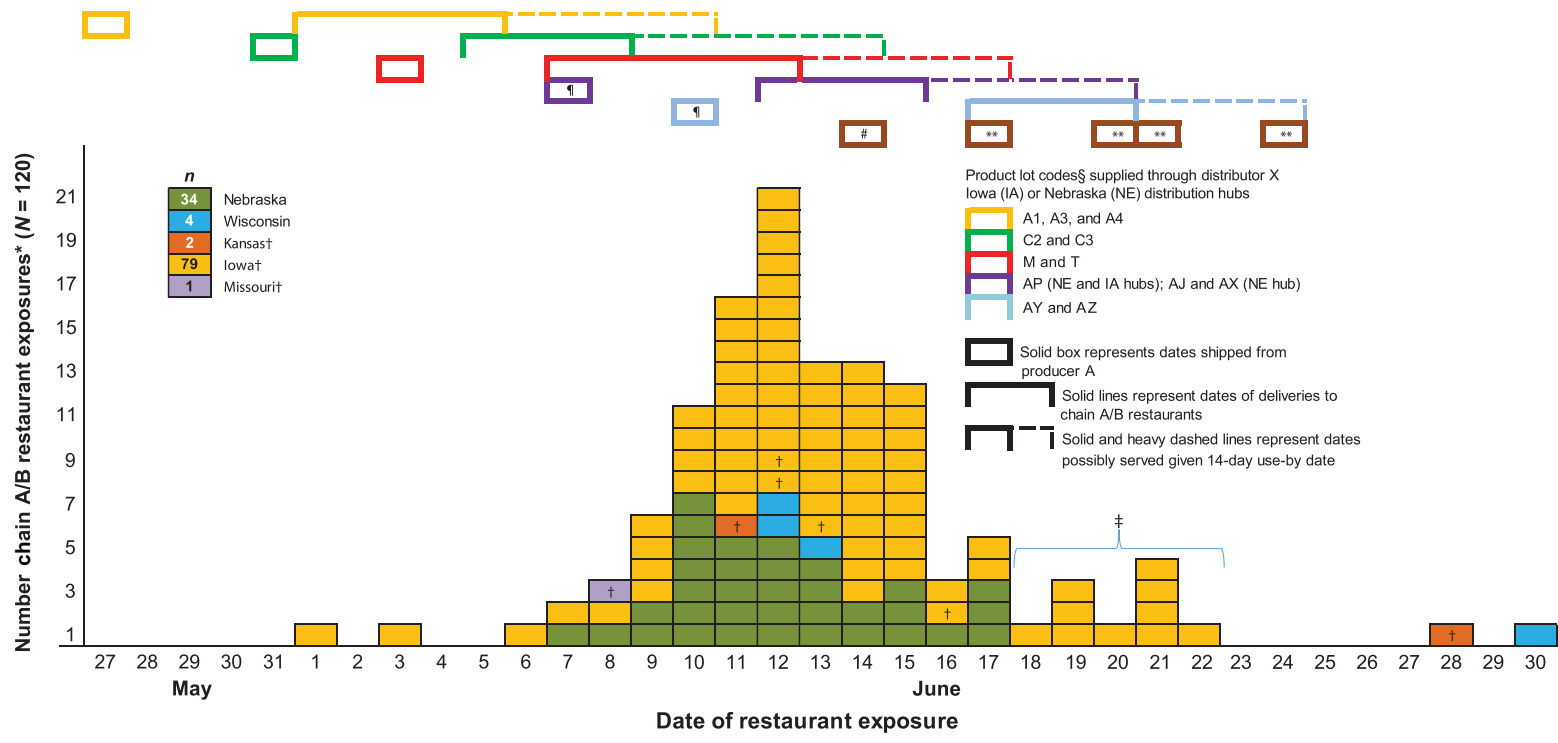

Fig. 4. Number of chain $\mathrm{A} / \mathrm{B}$ restaurant exposures* by dates of dining and timing of corresponding distributor $\mathrm{X}$ deliveries of producer A salad mix by production lot codes, May and June 2013. (* Chain A/B restaurant exposure defined as dining reported by a confirmed ill person who recalled exact date of patronage and house salad consumption within 14 days prior to illness onset. $†$ Six Iowa $(n=3)$, Kansas $(n=2)$ and Missouri $(n=1)$ residents reported exposure in Nebraska. One Iowan reported exposure in South Dakota on 13 June. \$ Ten Iowa residents dined 18-22 June 2013 in five restaurants all probably served by distributor $\mathrm{X}$ hubs that had received grower Y/ranch Z/lot $\mathrm{S}$ romaine-containing salad mix on both 7 and 10 June for subsequent delivery. $\S$ Lot specific restaurant delivery information was not retained by the distributor so only groups of lots reported as being delivered in shipments. If For product shipped both 7 and 10 June, grower Y/ranch Z/lot S romaine-containing products were shipped from producer A to distribution hubs in Nebraska, Iowa, and Illinois (Table 4). Restaurant-specific delivery information was not available for the Iowa or Illinois hubs to definitively link product to reported exposures. However, grower Y/ranch Z/lot S romaine was supplied by the Nebraska hub on both 14 and 17 June to an Iowa chain A/B restaurant where one confirmed ill Iowan reported exposure on 18 June 2013. \# For salad-mix product shipped on 14 June, no restaurant-specific delivery information was available except for the Nebraska hub. However, grower Y/ranch Z/lot S romaine-containing salad-mix product had been shipped by producer A for subsequent delivery from hubs in Nebraska, Iowa, Wisconsin, and Illinois. The Missouri hub also received a slightly larger amount from this shipment than each of the other distribution hubs but romaine grower was unknown. ** For product shipped on and after 17 June, no restaurant-specific delivery information was available. However, grower $\mathrm{Y} / \mathrm{ranch} \mathrm{Z} / \mathrm{lot} \mathrm{S}$ romaine was no longer included in any producer A salad-mix shipments.

definitive. In early June, romaine lettuce from a second grower R/ranch R growing field (lot Q; PC-A1 and PC-A2), presumably adjacent to the main implicated growing field (grower R/ranch R/lot R), was connected with illnesses in three Iowa residents who consumed chain A/B house salad during 1-6 June 2013, two of whom reported symptom onset before 9 June. With documentation that romaine from this field also shipped to the distributor X Nebraska hub (Supplementary Table S3, note), this contaminated product can also explain two cases in Nebraska residents reporting chain $\mathrm{A} / \mathrm{B}$ exposure and symptom onset before 9 June. With regard to late June onset cases and known chain $\mathrm{A} / \mathrm{B}$ house salad consumption after implicated PC-T salad mix would have been completely out of inventories, romaine lettuce from growers other than grower $\mathrm{R}$ was being supplied in producer A's salad mix. Our findings suggest grower Y/ranch $\mathrm{Z} /$ lot $\mathrm{S}$ as a plausible source of potentially contaminated product in these later shipments. Ultimately, our findings suggest that two separate growing fields of one grower and at least one additional field from an entirely different grower probably caused cyclosporiasis in all 169 persons who reported chain A/B exposure within the distributor $\mathrm{X}$ service area.

No information currently exists to explain what event or factors might have potentially contaminated two growers' romaine lettuce. On the basis of preliminary data and early investigation findings of a multistate investigation, an FDA Environmental Assessment (EA) was conducted during 12-19 August 2013 in Mexico; five ranches (three iceberg lettuce, one red cabbage, and one green leaf) and the producer A processing facility were inspected [8]. At that time, the investigation was 
Table 4. Romaine lettuce grower of producer A salad-mix shipments to distributor X distribution hubs by production lot code, shipping date, and state with number of linked cyclosporiasis cases per hub, Nebraska and Iowa region, 2013

\begin{tabular}{|c|c|c|c|c|c|c|}
\hline \multirow[b]{2}{*}{$\begin{array}{l}\text { Shipping } \\
\text { date, } 2013\end{array}$} & \multirow{2}{*}{$\begin{array}{l}\text { Production } \\
\text { lot code } \\
(\mathrm{PC})\end{array}$} & \multicolumn{5}{|c|}{$\begin{array}{l}\text { State of distributor X distribution hub } \\
\text { (no. of linked cases)* }\end{array}$} \\
\hline & & $\begin{array}{l}\text { Iowa } \\
(n=77)\end{array}$ & $\begin{array}{l}\text { Nebraska } \\
(n=72)\end{array}$ & $\begin{array}{l}\text { Wisconsin } \\
(n=4)\end{array}$ & $\begin{array}{l}\text { Illinois } \\
(n=3)\end{array}$ & $\begin{array}{l}\text { Missouri } \\
(n=0)\end{array}$ \\
\hline 27 May & $\mathrm{A} 1 \dagger$ & & & & & $\dagger$ \\
\hline 27 May & $\mathrm{A} 2 \dagger$ & & & & & $\dagger$ \\
\hline 27 May & $\mathrm{A} 3 \dagger$ & & & & & $\dagger$ \\
\hline 27 May & A4 $\dagger$ & & 1 & & & $\dagger$ \\
\hline 30 May & A5 & & & & & \\
\hline 30 May & A6 & & & & & \\
\hline 31 May & $\mathrm{C} 2$ & & & & & \\
\hline 31 May & C3 & & & & & \\
\hline 30 May & E1 & & & & & \\
\hline 30-31 May & G & & & & & \\
\hline 3 June & $\mathrm{M}$ & & & & & \\
\hline 3 June & $T \S$ & & & & & \\
\hline 3 June & $\mathrm{U}$ & & & & & \\
\hline 3 June & V & & & & & \\
\hline 3 June & $\mathrm{AE}$ & & & & & \\
\hline 3 June & $\mathrm{AF}$ & & & & & \\
\hline 7 June & AJ & & & & & \\
\hline 7 June & AK & & & & & \\
\hline 7 June & AN & & & & & \\
\hline 7 June & $\mathrm{AO}$ & & & & & \\
\hline 7 June & $\mathrm{AP}$ & & & & & \\
\hline 7 June & $\mathrm{AW}$ & & & & & \\
\hline 7 June & $\mathrm{AX}$ & & & & & \\
\hline 10 June & AAA $\dagger$ & & & & & $\dagger$ \\
\hline 10 June & $\mathrm{AAB}^{\dagger}$ & & & & & $\dagger$ \\
\hline 10 June & $\mathrm{AY} \oplus$ & & & & & $\dagger$ \\
\hline 10 June & $\mathrm{AZ} \dagger$ & & & & & $\dagger$ \\
\hline
\end{tabular}

Grower R/ranch R/lot R; $₫$, grower R/ranch R/lot Q; $\square$, grower Y/ranch Z/lot S; $\square$, other growers not linked to cases; $\square$, no shipment

* Thirteen (7.7\%) of 169 confirmed ill persons who reported chain A/B exposure could not recall exact location of dining.

$\dagger$ Romaine grower unknown for all $\mathrm{PC} \mathrm{A} 1, \mathrm{~A} 2, \mathrm{~A} 3, \mathrm{~A} 4, \mathrm{AAA}, \mathrm{AAB}, \mathrm{AY}$, and $\mathrm{AZ}$ saladmix boxes shipped to the Missouri hub.

\$ On 27 May, producer A chopped romaine (not salad mix) originating from grower $\mathrm{R} /$ ranch R/lot $\mathrm{Q}$ was shipped to the Nebraska distribution hub for chain $\mathrm{A} / \mathrm{B}$ delivery (PC A4A).

$\S$ Boxes of PC-T salad-mix product shipped to all but the Missouri hub contained iceberg lettuce from three different growers: grower $\mathrm{P} /$ ranch $\mathrm{P} /$ lot 1, grower $\mathrm{D} /$ ranch $\mathrm{K} /$ lot $\mathrm{E}$, and grower U/ranch B/lot B (See Supplementary Table S2). 
using data that contained some erroneous grower information. As such, romaine lettuce was not suspected as a likely vehicle so romaine-growing ranches were not included in the EA. At inspected locations, no potential sources of the outbreak pathogen nor significant potential routes of contamination of salad products were identified [8]. Further, we have no information to establish either the relative locations of grower R/ranch R/lots R or $\mathrm{Q}$ or grower $\mathrm{Y} /$ ranch $\mathrm{Z} /$ lot $\mathrm{S}$ or even their proximity to either the processing facility or the inspected ranches.

Despite lack of information regarding the romaine lettuce growing environments, our findings and the lifecycle of C. cayetanensis suggest possible explanations. Infected individuals excrete unsporulated oocysts which then require days to weeks under favourable conditions to sporulate and thus become infective; under laboratory conditions, $7-15$ days with an optimum temperature of $23-27{ }^{\circ} \mathrm{C}$ [5]. Given these characteristics, refrigeration temperatures used after harvest and processing would likely not provide suitable conditions for sporulation and thus contamination of the illness-associated romaine lettuce would have had to occur in the days prior to packaging. C. cayetanensis oocysts are resistant to many disinfectants including chlorination at concentrations used for routine disinfection, so any sporulated oocysts that remained after washing and processing prior to being subjected to refrigeration would still retain infectivity once subjected to lower temperatures [7]. Given that romainecontaining products were generally shipped and thus refrigerated within $24 \mathrm{~h}$ after harvest [e.g. harvested 26 May and 2 June; shipped 27 May and 3 June (ranch lots $\mathrm{Q}$ and $\mathrm{R}$, respectively)], contamination with unsporulated oocysts only at the times of harvest, preprocessing transport, or processing would be unlikely to subsequently yield infective oocysts or cause infection. Further, our findings do not suggest that cross-contamination with infective oocysts occurred during such handling of other growers' romaine either; a single growing field was linked to the majority of cases despite being processed and shipped contemporaneously with romaine lettuce that was harvested from grower $\mathrm{Y} /$ ranch $\mathrm{Z} /$ lot $\mathrm{R}$ and subsequently included in large volumes of salad mix (PC-AE and PC-AF) supplied to the Missouri distribution hub (Supplementary Table S1). Given these insights, we believe that contamination most likely occurred prior to harvest while the romaine lettuce was still in the growing fields and a single point-source contamination event is unlikely.

Possible scenarios for pre-harvest contamination in two presumably adjacent growing fields and a third field from a seemingly unrelated grower include totally independent contamination events; shared, contaminated irrigation water; or a regional, rainwater run-off event involving at least these three fields. To better define potential sources of romaine lettuce pre-harvest contamination and to develop mitigation strategies for prevention, production practices of both growers $\mathrm{R}$ and $\mathrm{Y}$ should be investigated focusing on irrigation water sources and potential for contamination. A retrospective review of meteorological conditions in the growing regions during the pre-harvest period should be included.

Erroneous data was initially provided to FDA in the early phases of the multistate outbreak investigation (August 2013) thus precluding timely identification of a source. We suspect errors resulted from data entry or other unintentional mistakes. Receipt of corrected grower data in November 2013 allowed us to retrospectively implicate a source farm and growing field. The initial failure to implicate the source of contamination because of erroneous supply chain data underscores a potential critical limitation of epidemiologic investigations and highlights the need for public health authorities to validate the accuracy and integrity of such data. This limitation also underscores the need for producers to develop systems that efficiently capture accurate supply chain data using automated electronic systems to eliminate potential data inaccuracies caused by human error. With respect to final distribution, comprehensive, lot code-specific information was lacking at points-of-service. Consequently, we were unable to define when specific lot codes were in service, or to establish grower-specific attack rates. Further, grower information was completely lacking for 27 May Missouri distribution hub salad-mix shipments, so receipt and distribution of grower R/ranch R/lot Q romaine could not be excluded. Finally, the number of illnesses reported outside the time period of possible service of PC-T was insufficient to conduct additional case-control studies and distributor $\mathrm{X}$ chain $\mathrm{A} / \mathrm{B}$ delivery information was not available in Iowa to study connection to later-occurring cases.

Our findings link the majority of 2013 cyclosporiasis cases in the Upper Midwest of the United States to romaine lettuce of Mexican origin. Our investigation's success resulted from correlating occurrence of illnesses (or lack therefore) to product distribution rather than points-of-service. By implicating producer A-supplied romaine lettuce, we enabled product traceforward that further linked this source to exposures of additional ill persons beyond Midwest chain A/B restaurants, 
including points-of-service supplied by other distribution channels in Florida, Texas, and Nebraska [10]. A report from Texas also linked at least 25 cases during 2013 to imported cilantro [3]. When combined, collective 2013 investigative findings link contaminated fresh produce imported into the United States from two independent sources in Mexico - to at least 214 US cyclosporiasis cases during the summer of 2013 (romaine lettuce, $n=$ 189 ; cilantro, $n=25$ ) $[3,10]$. Collective findings of traceforward investigations further suggest producer A-supplied romaine lettuce as possible sources of exposure for all 20 US residents with illness onsets on or before 8 June 2013 and 135 other persons throughout 18 central and eastern US states with illness onset during 11 June-1 July 2013 [10].

\section{SUPPLEMENTARY MATERIAL}

For supplementary material accompanying this paper visit http://dx.doi.org/10.1017/S0950268815002484.

\section{ACKNOWLEDGEMENTS}

We gratefully thank Karis Bowen for GIS support and Dr Kirk Smith for expert review of this manuscript prior to publication. We also thank our colleagues in the Nebraska Public Health Laboratory, Iowa Hygienic Laboratory, and Nebraska Department of Agriculture for their substantial contributions. Further, we thank the vast number of professional colleagues who collaborated extensively in this investigation within our own agencies; in Nebraska and Iowa local health departments; in our neighbouring states of South Dakota, Kansas, Illinois, Missouri, and Wisconsin; and at CDC and FDA. Finally, we thank the healthcare providers and clinical laboratories throughout Nebraska, Iowa, Wisconsin, Kansas, and Missouri for their vigilance and diligence in diagnosing and reporting cyclosporiasis cases as reported in this paper; all the restaurants, their parent company, the producer, and the distributor for cooperating fully with our investigation and providing all requested and necessary product distribution information to facilitate traceback and traceforward efforts; and all ill persons and their dining partners who provided information regarding their illnesses and exposures upon being interviewed.

The findings and conclusions in this report are those of the authors and do not necessarily represent the official position of the Centers for Disease Control and Prevention. Likewise, the authors' findings and conclusions do not necessarily represent the views of the Nebraska Department of Health and Human Services, Iowa Department of Public Health, Iowa Department of Inspections and Appeals, or Douglas County Health Department.

\section{DECLARATION OF INTEREST}

None.

\section{REFERENCES}

1. Centers for Disease Control and Prevention. Notes from the field: outbreaks of cyclosporiasis - United States, June-August 2013. Morbidity and Mortality Weekly Report 2013; 62: 862.

2. Centers for Disease Control and Prevention. Cyclosporiasis outbreak investigations-United States, 2013 (final update) (http://www.cdc.gov/parasites/cyclosporiasis/ outbreaks/investigation-2013.html). Accessed 20 May 2015.

3. Abanyie F, et al. 2013 multistate outbreaks of Cyclospora cayetanensis infections associated with fresh produce: focus on the Texas investigations. Epidemiology and Infection 2015. Published online: 13 April 2015. doi:10.1017/S0950268815000370.

4. U.S. Food and Drug Administration. FDA investigates multistate outbreak of cyclosporiasis (http://www.fda. gov/food/recallsoutbreaksemergencies/outbreaks/ucm 36 1637.htm\#updates). Accessed 20 May 2015.

5. Ortega YR, Sanchez R. Update on Cyclospora cayetanensis, a food-borne and waterborne parasite. Clinical Microbiology Reviews 2010; 23: 218-234.

6. Herwaldt BL. Cyclospora cayetanensis: a review, focusing on the outbreaks of cyclosporiasis in the 1990s. Clinical Infectious Diseases 2000; 31: 1040-1057.

7. Herwaldt BL. The ongoing saga of U.S. outbreaks of cyclosporiasis associated with imported fresh produce: what Cyclospora cayetanensis has taught us and what we have yet to learn. In: Addressing Foodborne Threats to Health: Policies, Practices, and Global Coordination. Washington, DC: National Academies Press, 2006, pp. 85-115, 133-140.

8. U.S. Food and Drug Administration. Environmental assessment: 2013 cyclosporiasis outbreak in Iowa and Nebraska - findings and recommendations (http://www. fda.gov/Food/RecallsOutbreaksEmergencies/Outbreaks/ ucm375732.htm). Accessed 20 May 2015.

9. Iowa Department of Public Health. Iowa Cyclospora outbreak 2013 (outbreak update 30 July 2013) (http:// www.idph.state.ia.us/IDPHChannelsService/file.ashx?file= 24BC0E1B-20FA-423A-88D2-D8C690A30E11). Accessed 20 May 2015.

10. Buss BF, et al. Multistate product traceforward investigation to link imported romaine lettuce to a US cyclosporiasis outbreak - Nebraska, Texas, and Florida, June-August 2013. Epidemiology and Infection. doi:10.1017/S0950268815002320. 